\title{
Developing digital signal clustering method using local binary pattern histogram
}

\author{
Rashad J. Rasras ${ }^{1}$, Bilal Zahran ${ }^{2}$, Mutaz Rasmi Abu Sara ${ }^{3}$, Ziad AlQadi ${ }^{4}$ \\ ${ }_{1,2,4}$ Department of Computer Engineering, Al-Balqa Applied University, Jordan \\ ${ }^{3}$ Department of Computer Science, Taibah University, Saudi Arabia
}

\begin{tabular}{|c|c|}
\hline Article Info & ABSTRACT \\
\hline Article history: & In this paper we presented a new approach to manipulate a digital signal in \\
\hline Received Feb 25, 2020 & $\begin{array}{l}\text { order to create a features array, which can be used as a signature to retrieve } \\
\text { the signal. Each digital signal is associated with the local binary pattern }\end{array}$ \\
\hline Revised Aug 9, 2020 & (LBP) histogram; this histogram will be calculated based on LBP operator, \\
\hline Accepted Aug 17, 2020 & $\begin{array}{l}\text { then k-means clustering was used to generate the required features for each } \\
\text { digital signal. The proposed method was implemented, tested and }\end{array}$ \\
\hline Keywords: & $\begin{array}{l}\text { the obtained experimental results were analyzed. The results showed } \\
\text { the flexibility and accuracy of the proposed method. Althoug different }\end{array}$ \\
\hline Feature extraction & $\begin{array}{l}\text { parameters of the digital signal were changed during implementation, } \\
\text { the results obtained showed the robustness of the proposed method. }\end{array}$ \\
\hline
\end{tabular}

This is an open access article under the CC BY-SA license.

K-means clustering
Local binary pattern (LBP)

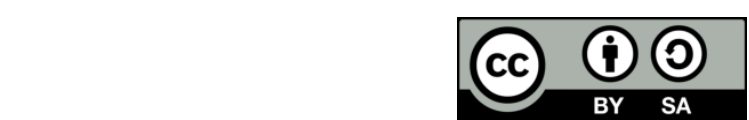

\section{Corresponding Author:}

Rashad J. Rasras,

Department of Computer Engineering,

Al-Balqa Applied University,

Amman, Jordan.

Email: rashad.rasras@bau.edu.jo

\section{INTRODUCTION}

Digital signals such as digital color images and digital wave signals are used usually in various computer applications such as computer security and others. Because of the big size of the wave file it is very difficult to use thr whole file for retrieval or recognition purposes; here the importance of extracting file features appears [1]. Digital wave signal usually represented by mono or stereo. Mono describes a system where all the audio signals are mixed together and routed through a single audio channel. Stereo sound systems have two independent audio channels, and the signals are reproduced by two channels separated by some distance [2]. The amplitude values of each column are ranges from -1 to +1 and they are the results of sampling and quantization of the voice signal. Figure 1 shows some samples of a given wave file.

While Figures 2 and 3 show the wave of the voice signal. One of the most used applications related to digital wave signals processing is voice retrieval and recognition. Most of these applications use the nature of the digital wave file to generate some features for the file by mean of calculating some parameters such as crest factor, dynamic range, mean of the normalized data (sigma), and standard deviation of the normalized data $(\mathrm{Mu})$, these parameters can be easily calculated and used as a features for digital wave signal [1-3]. Calculating these statistical parameters requires understanding digital voice characteristics and nature, and some time they do not give an acceptable recognition ratio if we use them to recognize the voice even if they give stable and fixed features for each wave file. These features will remain the same even if we change sampling frequency, amplitude or phase shifting as shown in Tables 1 and 2. 


$\begin{array}{rr}-0.0038 & -0.0057 \\ -0.0038 & -0.0038 \\ 0 & -0.0038 \\ 0 & 0 \\ -0.0019 & -0.0038 \\ -0.0038 & -0.0038 \\ -0.0019 & -0.0019 \\ -0.0057 & -0.0057 \\ -0.0038 & -0.0038 \\ -0.0019 & -0.0057\end{array}$

Figure 1. Samples of a stereo wave file

The signal in the time domain

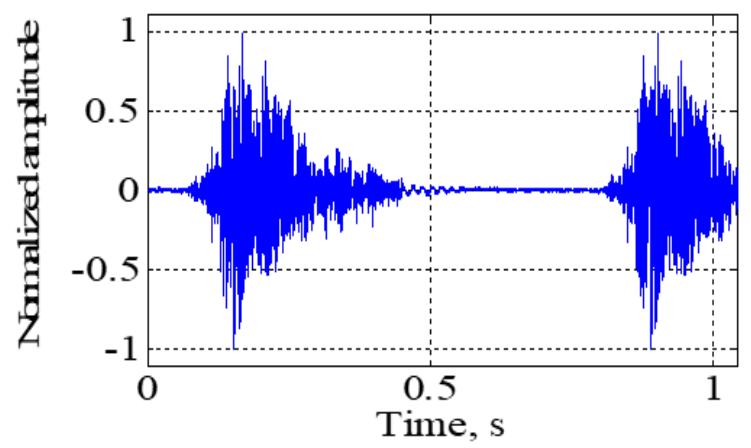

Figure 2. Voice wave signal in time domain

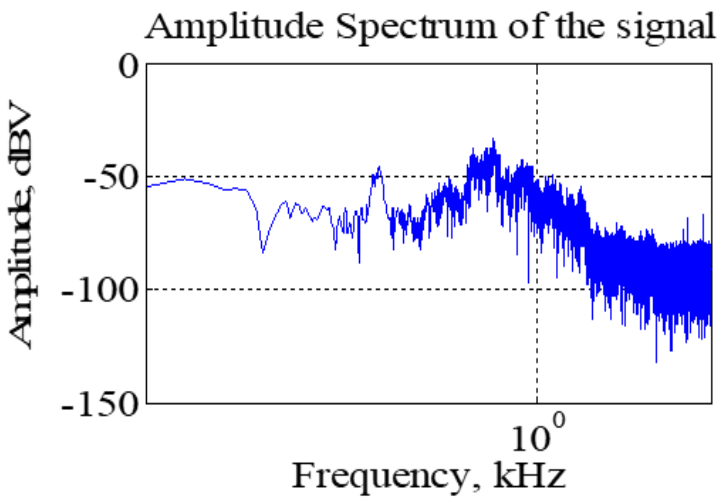

Figure 3. Voice wave signal in frequency domain

Table 1. Statistical features

\begin{tabular}{lllll}
\hline Wave file & & \multicolumn{4}{c}{$\begin{array}{c}\text { Features } \\
\text { Sigma }\end{array}$} & Mu & Peak (crest) factor (dB) & Dynamic range (dB) \\
\hline Cow & 0.39533 & -0.00026786 & 8.0609 & 84.2881 \\
Dog & 0.1656 & $-6.597 \mathrm{e}-005$ & 15.6188 & 49.8906 \\
Duck & 0.076118 & 0.00023276 & 22.3703 & 49.0724 \\
Dolphin & 0.17197 & -0.00166 & 15.2905 & 46.229 \\
Horse & 0.41379 & 0.0026426 & 7.6645 & 42.1439 \\
\hline
\end{tabular}

Table 2. Statistical features for the same file with varying sampling frequency

\begin{tabular}{lccll}
\hline $\begin{array}{l}\text { Cow wave file } \\
\text { sampling frequency }\end{array}$ & Sigma & $\mathrm{Mu}$ & $\begin{array}{c}\text { Features } \\
\text { Peak (crest) factor }(\mathrm{dB})\end{array}$ & \begin{tabular}{l} 
Dynamic range $(\mathrm{dB})$ \\
\hline 11025
\end{tabular} \\
0.39533 & -0.00026786 & 8.0609 & 84.2881 \\
15000 & 0.39533 & -0.00026786 & 8.0609 & 84.2881 \\
20000 & 0.39533 & -0.00026786 & 8.0609 & 84.2881 \\
1000 & 0.39533 & -0.00026786 & 8.0609 & 84.2881 \\
2000 & 0.39533 & -0.00026786 & 8.0609 & 84.2881 \\
\hline
\end{tabular}

To overcome the above mentioned disadvantages, we can extract the voice signal features based on local binary pattern (LBP). Here we can calculate LBP histogram to be used as an input data set to generate the digital file features. LBP and its variants such as completed noise-invariant local-structure pattern (CNLP) [4], and dominant LBP (DLBP) [5] has been favorably applied to a wide variety of applications, such as texture classification [6-13], face analysis [14-16], speech recognition [9, 10] and others [17, 19]. The LBP encodes the co-occurrence of neighboring pixel comparisons within a local area. It is computationally efficient, simple, and robust against some parameters changes. A cluster refers to a collection of data points combined together because of certain similarities. A centroid is the location representing the center of the cluster. K-means algorithm identifies $\mathrm{k}$ number of centroids, and then allocates every data point to the nearest cluster, while keeping the centroids as small as possible [20-25]. 


\section{PROPOSED METHOD}

The proposed method can be implemented by applyig the following 2 phases:

Phase 1: LBP histogram calculation.

This phase can be implemented performing the following steps:

a. Get the digital wave file.

b. Reshape the wave file into one row array.

c. For each value in the row calculate LBP operator as shown in Figure 4

\begin{tabular}{|c|c|c|c|c|c|c|c|c|c|c|c|c|c|c|}
\hline $\mathrm{i}-4$ & $\mathrm{i}-3$ & $\mathrm{i}-2$ & $\mathrm{i}-1$ & $\mathbf{i}$ & $\mathrm{i}+1$ & $\mathrm{i}+2$ & $\mathrm{i}+3$ & $\mathrm{i}+4$ &. &. &. &. &. &. \\
\hline 0.9 & -0.8 & 1 & 0.3 & $\mathbf{0 . 5}$ & 0.89 & -0.6 & 0.75 & 0.65 &. &. &. &. &. &. \\
\hline 1 & 0 & 1 & 0 & $\begin{array}{c}\text { Selected } \\
\text { value }\end{array}$ & $\mathbf{1}$ & $\mathbf{0}$ & $\mathbf{1}$ & $\mathbf{1}$ &. &. &. &. &. &. \\
\end{tabular}

Figure 4. LBP histogram calculation

d. Add one to the repetition of LBP operator value.

Figure 5 shows the calculated LBP histogram of the duck wave file.

Phase 2: K-means clustering

Clustering means grouping the data values in the input data file into clusters (groups) [20-25], each cluster will have a center (centroid), set of values which are belong to and within a cluster sum(sum of the values belong to the cluster), one or more of these parameters can be used to form the data file features. Figure 6 shows how a data input set was grouped into 2 clusters:

To perform the clustering phase we have to apply the following steps:

1) Get the LBP histogram of the digital voice signal.

2) Initialize the number of clusters and the centroid of each cluster.

3) While there are a changes in the calculated centroids do the following:

a) Calculate the distances between each data set value and cluster centroid, which is equal to absolute value of the deference between the center and the data item value.

b) Select the value nearest cluster, the minimum distance the minimum cluster number.

c) Find the new centroids by averaging the values within the clusters.

Worked example:

The following example shows how to group the input data into 2 clusters with the following centroids initial values Tables 3 and 4:

$\mathrm{c} 1=16$

$\mathrm{c} 2=22$

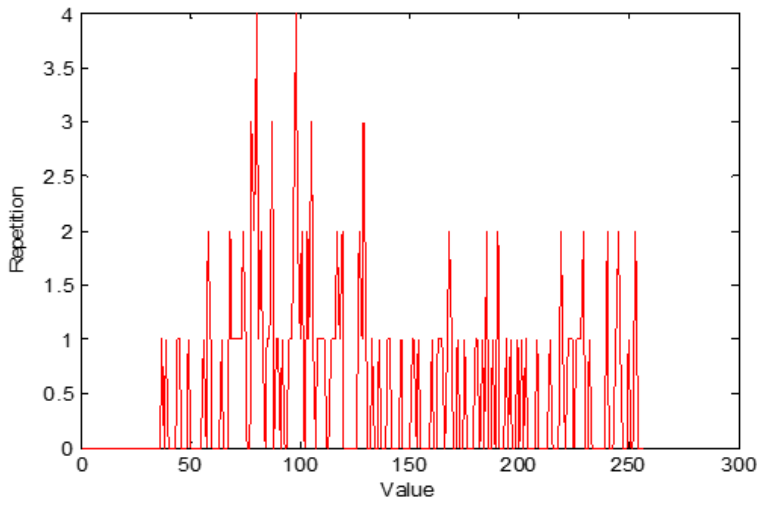

Figure 5. LBP histogram of duck wave file

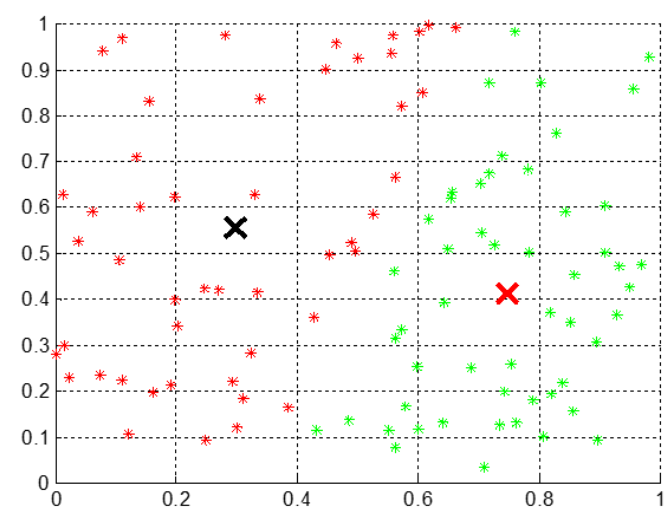

Figure 6. Grouping input data set into 2 clusters 
Table 3. Worked example passes 1 and 2

\begin{tabular}{|c|c|c|c|c|c|c|c|c|c|}
\hline \multicolumn{5}{|c|}{ Pass 1} & \multicolumn{5}{|c|}{ Pass 2} \\
\hline 15 & 1 & 7 & 1 & & 15 & 0.33 & 21.25 & 1 & 18.56 \\
\hline 15 & 1 & 7 & 1 & & 15 & 0.33 & 21.25 & 1 & 45.9 \\
\hline 16 & 0 & 6 & 1 & & 16 & 0.67 & 20.25 & 1 & \\
\hline 19 & 3 & 3 & 2 & & 19 & 3.67 & 17.25 & 1 & \\
\hline 19 & 3 & 3 & 2 & & 19 & 3.67 & 17.25 & 1 & \\
\hline 20 & 4 & 2 & 2 & & 20 & 4.67 & 16.25 & 1 & \\
\hline 20 & 4 & 2 & 2 & & 20 & 4.67 & 16.25 & 1 & \\
\hline 21 & 9 & 1 & 2 & & 21 & 5.67 & 15.25 & 1 & \\
\hline 22 & 6 & 0 & 2 & & 22 & 6.67 & 14.25 & 1 & \\
\hline 28 & 12 & 6 & 2 & 15.33 & 28 & 12.67 & 8.25 & 2 & \\
\hline 35 & 19 & 13 & 2 & 36.25 & 35 & 19.67 & 1.25 & 2 & \\
\hline 40 & 24 & 18 & 2 & & 40 & 24.67 & 3.75 & 2 & \\
\hline 41 & 25 & 19 & 2 & & 41 & 25.67 & 4.75 & 2 & \\
\hline 42 & 26 & 20 & 2 & & 42 & 26.67 & 5.75 & 2 & \\
\hline 43 & 27 & 21 & 2 & & 43 & 27.67 & 6.75 & 2 & \\
\hline 44 & 28 & 22 & 2 & & 44 & 28.67 & 7.75 & 2 & \\
\hline 60 & 44 & 38 & 2 & & 60 & 44.67 & 23.75 & 2 & \\
\hline 61 & 45 & 39 & 2 & & 61 & 45.67 & 24.75 & 2 & \\
\hline 65 & 49 & 43 & 2 & & 65 & 49.67 & 28.75 & 2 & \\
\hline
\end{tabular}

Table 4. Worked example passes 3 and 4

\begin{tabular}{|c|c|c|c|c|c|c|c|c|c|}
\hline \multicolumn{5}{|c|}{ Pass 3} & \multicolumn{5}{|c|}{ Pass 4} \\
\hline Data & D1 & $\mathrm{D} 2$ & Nearest cluster & New centroids & Data & D1 & D2 & Nearest cluster & New centroids \\
\hline 15 & 3.56 & 30.9 & 1 & 19.50 & 15 & 4.50 & 32.89 & 1 & 19.50 \\
\hline 15 & 3.56 & 30.9 & 1 & 47.89 & 15 & 4.50 & 32.89 & 1 & 47.89 \\
\hline 16 & 2.56 & 29.9 & 1 & & 16 & 3.50 & 31.89 & 1 & No changes, so \\
\hline 19 & 0.44 & 26.9 & 1 & & 19 & 0.50 & 28.89 & 1 & stop \\
\hline 19 & 0.44 & 26.9 & 1 & & 19 & 0.50 & 28.89 & 1 & \\
\hline 20 & 1.44 & 25.9 & 1 & & 20 & 0.50 & 27.89 & 1 & \\
\hline 20 & 1.44 & 25.9 & 1 & & 20 & 0.50 & 27.89 & 1 & \\
\hline 21 & 2.44 & 24.9 & 1 & & 21 & 1.50 & 26.89 & 1 & \\
\hline 22 & 3.44 & 23.9 & 1 & & 22 & 2.50 & 25.89 & 1 & \\
\hline 28 & 9.44 & 17.9 & 1 & & 28 & 8.50 & 19.89 & 1 & \\
\hline 35 & 16.44 & 10.9 & 2 & & 35 & 15.50 & 12.89 & 2 & \\
\hline 40 & 21.44 & 5.9 & 2 & & 40 & 20.50 & 7.89 & 2 & \\
\hline 41 & 22.44 & 4.9 & 2 & & 41 & 21.50 & 6.89 & 2 & \\
\hline 42 & 23.44 & 3.9 & 2 & & 42 & 22.50 & 5.89 & 2 & \\
\hline 43 & 24.44 & 2.9 & 2 & & 43 & 23.50 & 4.89 & 2 & \\
\hline 44 & 25.44 & 1.9 & 2 & & 44 & 24.50 & 3.89 & 2 & \\
\hline 60 & 41.44 & 14.1 & 2 & & 60 & 40.50 & 12.11 & 2 & \\
\hline 61 & 42.44 & 15.1 & 2 & & 61 & 41.50 & 13.11 & 2 & \\
\hline 65 & 46.44 & 19.1 & 2 & & 65 & 45.50 & 17.11 & 2 & \\
\hline
\end{tabular}

The calculated parameters are:

Centroids: $\mathrm{C} 1=19.50, \mathrm{C} 2=47.89$

Within cluster sums: WCS $1=195$, WSC2 $=431$

Number of points: Number of points in cluster $1=10$, Number of points in cluster $2=9$

\section{RESULTS ANALYSIS}

The proposed method was implemented using various digital wave files. Each time a LBP histogram was calculated and used for clustering, the main advantages of the proposed method is a flexibility, here we can use the centroids, or within clusters sums, or cluster points to create wave file features, also it is easy to adjust the number of clusters to expand the number of elements in the features array. The experimental results showed that the obtained features for each wave file are unique, thus they can be used as a key or signature to retrieve or recognize the wave file, and Table 5 shows the calculated features for some wave file samples. The proposed method was tested using the same wave file but with different sampling frequencies, Table 6 shows that the features for the wave file remain the same. Also the proposed method was tested using the same wave file but with different amplitudes, Table 7 shows that the features for the wave file remain the same. 
Table 5. Wave file features

\begin{tabular}{cllll}
\hline Wave file & \multicolumn{4}{c}{ Features (Centroids) } \\
& C1 & C2 & C3 & C4 \\
\hline Cow & 243 & 183 & 93 & 8 \\
Dog & 227 & 164 & 102 & 60 \\
Duck & 231 & 176 & 112 & 71 \\
Dolphin & 218 & 158 & 73 & 32 \\
Horse & 237 & 167 & 79 & 7 \\
Donkey & 229 & 177 & 121 & 66 \\
Elephant & 255 & 249 & 114 & 15 \\
Spock & 234 & 131 & 66 & 10 \\
\hline
\end{tabular}

Table 6. Wave file features when varying sampling frequency

\begin{tabular}{ccccc}
\hline $\begin{array}{c}\text { Wave file cow sampling } \\
\text { frequency }\end{array}$ & \multicolumn{4}{c}{ Features (Centroids) } \\
\hline 1000 & 243 & 183 & 93 & 8 \\
1500 & 243 & 183 & 93 & 8 \\
2000 & 243 & 183 & 93 & 8 \\
2500 & 243 & 183 & 93 & 8 \\
3000 & 243 & 183 & 93 & 8 \\
10000 & 243 & 183 & 93 & 8 \\
12000 & 243 & 183 & 93 & 8 \\
14000 & 243 & 183 & 93 & 8 \\
\hline
\end{tabular}

Table 7. Wave file features when varying amplitude

\begin{tabular}{clccc}
\hline Wave file cow Amplitude & \multicolumn{4}{c}{ Features (Centroids) } \\
& C1 & C2 & C3 & C4 \\
\hline Original & 243 & 183 & 93 & 8 \\
Added by 0.03 & 243 & 183 & 93 & 8 \\
Subtracted by 0.01 & 243 & 183 & 93 & 8 \\
Multiplied by 1.2 & 243 & 183 & 93 & 8 \\
Multiplied by 0.2 & 243 & 183 & 93 & 8 \\
Divided by 1.2 & 243 & 183 & 93 & 8 \\
Divided by 0.8 & 243 & 183 & 93 & 8 \\
\hline
\end{tabular}

\section{CONCLUSION}

A flexible, fixed, and accurate method of wave file features extraction was proposed and imelemented. The proposed method relies on LBP histogram. More than one parameter can be used to form the file features, and number of data items in the feature array can be easily adjustable. It was shown that the generated features for any wave file are unique, and they can be used as a signature to recognize the file. The signature is robust againist the change of sampling frequency and the file amplitude.

\section{REFERENCES}

[1] I. Guyon, et al., "Feature Extraction, Foundations and Applications," Springer, 2006.

[2] Rossing, Thomas, F. Richard Moore, and Paul A. Wheeler, "The Science of Sound," 3rd ed. San Francisco, CA: Addison-Wesley Developers Press, 2002.

[3] A. Al-Qaisi, S. A. Khawatreh, A. Sharadqah, Z. A. Alqadi, "Wave File Features Extraction using Reduced LBP," International Journal of Electrical and Computer Engineering (IJECE), vol. 8, no. 5, pp. 2780-2787, 2018.

[4] N. Shrivastava and V. Tyagi, "Noise-invariant structure pattern for image texture classification and retrieval," Multimedia Tools and Applications, vol. 75, no. 18, pp. 10887-10906, 2016.

[5] S. Liao, M. W. K. Law, and A. C. S. Chung, "Dominant local binary patterns for texture classification," IEEE Transactions on Image Processing, vol. 18, no. 5, pp. 1107-1118, 2009.

[6] T. Ojala, M. Pietikäinen, and T. Mäenpää, "Multiresolution gray-scale and rotation invariant texture classification with local binary patterns," IEEE Transactions on Pattern Analysis and Machine Intelligence, vol. 24, no. 7, pp. 971-987, 2002.

[7] Z. Guo, L. Zhang, and D. Zhang, "A completed modeling of local binary pattern operator for texture classification," IEEE Transactions on Image Processing, vol. 19, no. 6, pp. 1657-1663, 2010.

[8] Z. Guo, L. Zhang, and D. Zhang, "Rotation invariant texture classification using LBP variance (LBPV) with global matching," Pattern Recognition, vol. 43, no. 3, pp. 706-719, 2010.

[9] G. Zhao and M. Pietikäinen, "Dynamic texture recognition using local binary patterns with an application to facial expressions," IEEE Transactions on Pattern Analysis and Machine Intelligence, vol. 29, no. 6, pp. 915-928, 2007. 
[10] G. Zhao, M. Barnard, and M. Pietikäinen, "Lipreading with local spatiotemporal descriptors," IEEE Transactions on Multimedia, vol. 11, no. 7, pp. 1254-1265, 2009.

[11] G. Zhao, T. Ahonen, J. Matas, and M. Pietikäinen, "Rotation-invariant image and video description with local binary pattern features," IEEE Transactions on Image Processing, vol. 21, no. 4, pp. 1465-1477, 2012.

[12] T. Ojala, M. Pietikäinen, and D. Harwood, "A comparative study of texture measures with classification based on featured distributions," Pattern Recognition, vol. 29, no. 1, pp. 51-59, 1996.

[13] G. Kylberg and I. M. Sintorn, "Evaluation of noise robustness for local binary pattern descriptors in texture classification," EURASIP Journal on Image and Video Processing, vol. 2013, no. 17. 2013.

[14] X. Tan and B. Triggs, "Enhanced local texture feature sets for face recognition under difficult lighting conditions," IEEE Transactions on Image Processing, vol. 19, no. 6, pp. 1635-1650, 2010.

[15] H. Tang, B. Yin, Y. Sun, and Y. Hu, "3D face recognition using local binary patterns," Signal Processing, vol. 93, no. 8, pp. 2190-2198, 2013.

[16] T. Ahonen, A. Hadid, and M. Pietikäinen, "Face Description with Local Binary Patterns: Application to Face Recognition," in IEEE Transactions on Pattern Analysis and Machine Intelligence, vol. 28, no. 12, pp. 2037-2041, 2006.

[17] Sajida P., Nadeem N. and Jherna D., "Review on Local Binary Pattern (LBP) Texture Descritor and Its Variants," International Journal of Advanced Research (IJAR), vol. 5, no. 5, pp. 708-717, 2017.

[18] Y. Yin, X. Wang, D. Xu, F. Liu, Y. Wang, and W. Wu, "Robust visual detection-learning-tracking framework for autonomous aerial refueling of UAVs," IEEE Transactions on Instrumentation and Measurement, vol. 65, no. 3, pp. 510-521, 2016.

[19] B. Zahran, J. Al-Azzeh, Z. Alqadi and Mohd-Ashraf Al Zoghoul, "A Modified Lbp Method To Extract Features From Color Images," Journal of Theoretical and Applied Information Technology, vol. 96, no. 10, pp. 3014-3024, 2018.

[20] Madhuri A. Tayal, M. M. Raghuwanshi, "Review on Various Clustering Methods for the Image Data," Journal of Emerging Trends in Computing and Information Sciences, vol. 2, pp. 34-38, 2011.

[21] H. Tariq, S. Burney, "K-Means Cluster Analysis for Image Segmentation," International Journal of Computer Applications, vol. 96, no. 4, pp. 1-8, 2014.

[22] D. Sa'adillah Maylawati, T. Priatna, H. Sugilar, M. Ali Ramdhani," Data science for digital culture improvement in higher education using K-means clustering and text analytics," International Journal of Electrical and Computer Engineering (IJECE), vol. 10, no. 5, pp. 4569-4580, 2020.

[23] A. Abdul-hussian Hassan, W. Md Shah, M. Fairuz Iskandar Othman, and H. Hassan, "Evaluate the performance of K-Means and the fuzzy C-Means algorithms to formation balanced clusters in wireless sensor networks," International Journal of Electrical and Computer Engineering (IJECE), vol. 10, no. 2, pp. 1515-1523, 2020.

[24] E. Cherrat, R. Alaoui, and H. Bouzahir, "Improving of Fingerprint Segmentation Images Based on K-means and DBSCAN Clustering," International Journal of Electrical and Computer Engineering (IJECE), vol. 9, no. 4, pp. 2425-2432, 2019.

[25] I. Qays Abduljaleel, and A. Hameed Khaleel, "Hiding text in speech signal using K-means, LSB techniques and chaotic maps," International Journal of Electrical and Computer Engineering (IJECE), vol. 10, no. 6, pp. 5726-5735, 2020 .

\section{BIOGRAPHIES OF AUTHORS}

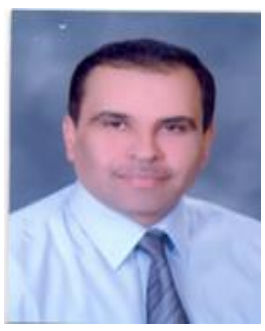

Rashad J. Rasras received the $\mathrm{PhD}$ degree from National Technical University (Kharkov Polytechnic Institute) in 2001, with research in automated intelligent control systems. His research interest includes image processing, machine learning, and advanced computer architecture. He works as an associative professor at Computer Engineering department, Al-Balqa Applied University.

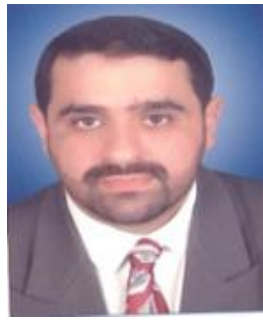

Bilal Zahran received the B.Sc degree in Electrical \& Electronic Eng. from Middle East Technical University, Turkey, in 1996, the M.Sc degree in Communications Eng. from University of Jordan, Jordan, in 1999, and the PhD degree in Computer Information System (CIS) from Arab Academy for Banking and Financial Sciences, Jordan, in 2009. He is currently working as an Associate Professor at department of Computer Engineering, Faculty of Engineering Technology, Al-Balqa Applied University, Jordan. His research interests include artificial intelligence, optimization and digital signal processing fields.

Email: zahranb@bau.edu.jo,/zahranb@yahoo.com 


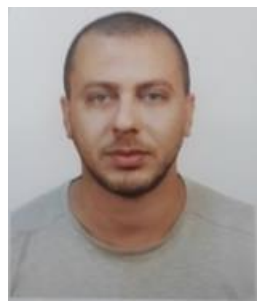

Mutaz Rasmi Abu Sara received the B.Sc from Saint Petersburg Electrotechnical University in 2004. He received the Master of Science (Database Systems) from Saint Petersburg Electrotechnical University in 2006. After working as programmer at BiSoft Company in Saint Petersburg. He received the Phd in Saint Petersburg Electrotechnical University from 2007) with Research and Development of Integrated Database Circuit Components for CAD Schematic. His research interest includes Database Systems, Algorithms and Data Structures and Optimization. He works as assistant professor from 2011 till now at Taibah University.

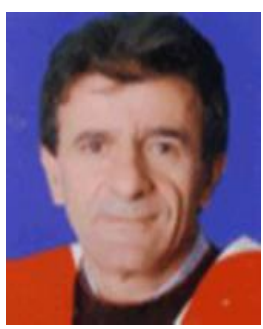

Ziad AlQadi is currently working as a Professor at Computer Engineering Department, Faculty of Engineering Technology, Al-Balqa Applied University. He is the Head of Computer engineering department. His research interests include Signal processing, parallel processing, image processing 